\title{
Utilization of Structure-Based Design to Identify Novel, Irreversible Inhibitors of EGFR Harboring the T790M Mutation
}

\author{
Edward J. Hennessy, ${ }^{*}{ }^{\dagger}$ Claudio Chuaqui, ${ }^{\dagger}$ Susan Ashton, ${ }^{\ddagger}$ Nicola Colclough, ${ }^{\ddagger}$ Darren A. E. Cross, ${ }^{\ddagger}$ \\ Judit É. Debreczeni, ${ }^{\ddagger}$ Cath Eberlein, ${ }^{\ddagger}$ Lakshmaiah Gingipalli, ${ }^{\dagger}$ Teresa C. M. Klinowska, \\ Jonathan P. Orme, ${ }^{\dagger}$ Li Sha, ${ }^{\dagger}$ and Xiaoyun $\mathrm{Wu}^{\dagger}$ \\ ${ }^{\dagger}$ Oncology iMed, Innovative Medicines \& Early Development, AstraZeneca R\&D Boston, 35 Gatehouse Drive, Waltham, \\ Massachusetts 02451, United States \\ ${ }^{\ddagger}$ Oncology iMed \& Discovery Sciences, Innovative Medicines \& Early Development, AstraZeneca, Mereside, Alderley Park, \\ Macclesfield, Cheshire SK10 4TG, United Kingdom
}

Supporting Information

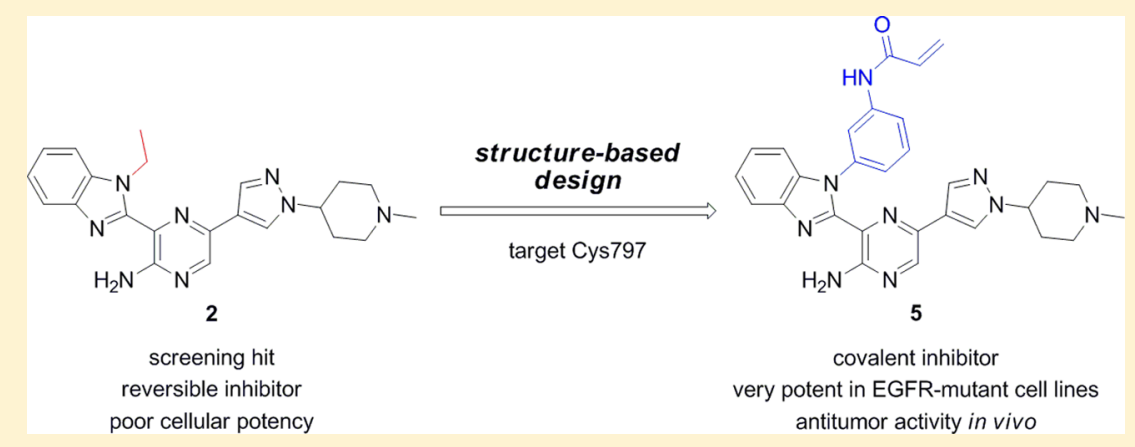

ABSTRACT: A novel series of covalent inhibitors of EGFR (epidermal growth factor receptor) kinase was discovered through a combination of subset screening and structure-based design. These compounds preferentially inhibit mutant forms of EGFR (activating mutant and T790M mutant) over wild-type EGFR in cellular assays measuring EGFR autophosphorylation and proliferation, suggesting an improved therapeutic index in non-small cell lung cancer patients would be achievable relative to established EGFR inhibitors. We describe our design approaches, resulting in the identification of the lead compound $\mathbf{5}$, and our efforts to develop an understanding of the structure-activity relationships within this series. In addition, strategies to overcome challenges around metabolic stability and aqueous solubility are discussed. Despite limitations in its physical properties, $\mathbf{5}$ is orally bioavailable in mice and demonstrates pronounced antitumor activity in in vivo models of mutant EGFR-driven cancers.

KEYWORDS: Non-small cell lung cancer, epidermal growth factor receptor, T790M mutation, covalent kinase inhibitors, structure-based drug design, aminopyrazines

$\mathrm{F}$ or the population of non-small cell lung cancer patients whose tumors harbor activating mutations in the epidermal growth factor receptor (EGFR), targeted kinase inhibitors such as gefitinib and erlotinib have proven to be very effective treatments resulting in tumor regressions and improved progression-free survival. ${ }^{1}$ Unfortunately, however, these effects are invariably short-lived, as drug resistance typically arises after about 1 year of treatment. Among the known causes for this acquired resistance, ${ }^{2,3}$ a secondary mutation at the gatekeeper residue of the kinase is responsible for roughly half of the instances of disease progression. ${ }^{4}$ This mutation (T790M) results in an increased affinity of the kinase toward ATP, rendering these ATP-competitive inhibitors less effective despite comparable affinities to the different mutant forms of the protein. ${ }^{5}$ The use of higher doses of these compounds to overcome this increased ATP affinity is precluded by their inhibition of wild-type (WT) EGFR, which is associated with clinical dose-limiting toxicities of skin rash and diarrhea. ${ }^{6}$
A strategy that has successfully been employed to target the T790M mutation has been to increase the intrinsic potency of inhibitors by inclusion of an electrophilic group capable of forming a covalent bond with a conserved cysteine residue (Cys797) present in EGFR. Irreversible inhibition of the kinase results in sustained occupancy of the ATP-binding site, thus overcoming the increased ATP affinity for EGFR T790M. This tactic has been applied to a number of known EGFR inhibitor scaffolds, and these efforts have been the subject of recent reviews. ${ }^{7-9}$ However, because Cys797 is present in EGFR WT as well, the clinical benefit of many of such irreversible inhibitors has been limited by suboptimal efficacy at maximally tolerated doses. $^{10,11}$ As a result, there has been a renewed interest in identifying irreversible inhibitors that would target EGFR

Received: February 9, 2016

Accepted: March 21, 2016

Published: March 21, 2016 
T790M while sparing EGFR WT, ${ }^{12-19}$ with the expectation that a larger therapeutic index would be achieved. We have previously described our efforts toward this goal within a series of anilinopyrimidine-based compounds, ${ }^{20}$ culminating in the identification of a compound that has been recently approved for the treatment of T790M patients (AZD9291/osimertinib, Tagrisso). ${ }^{21,22}$

As part of our project strategy to carry multiple chemical series forward into lead optimization, we explored a variety of scaffolds in addition to the series previously described. Among the compounds with inhibitory activity against EGFR T790M identified in our initial screening efforts, we chose to conduct further investigation on compounds based on an aminopyrazine hinge-binding core that had been studied previously within AstraZeneca. ${ }^{23}$ Exemplars from this series had promising activity in an EGFR T790M/L858R enzyme assay (e.g., compounds 1 and 2, Figure 1), and in general were 5- to 10-fold selective over

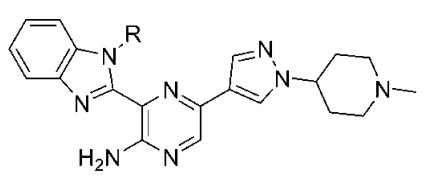

1, R = H; EGFR (T790M/L858R) IC $\mathrm{C}_{50}=0.29 \mu \mathrm{M}$

2, R = Et; EGFR (T790M/L858R) IC $\mathrm{C}_{50}=0.05 \mu \mathrm{M}$

Figure 1. Reversible aminopyrazine hits identified from initial screen.

EGFR WT (see Supporting Information). However, a substantial dropoff in potency was observed when compounds from this series were tested for activity in the NCI-H1975 ("double mutant") cell line, which harbors both the L858R activating mutation as well as the T790M gatekeeper mutation in EGFR. This phenomenon has been observed with previously described reversible inhibitors, and has been attributed to the aforementioned increased affinity of EGFR T790M for ATP and the higher levels of ATP present in cells compared to that used in the enzyme assay. ${ }^{20,24}$ In order to enhance the cellular activity of this series of compounds, therefore, we set about designing irreversible variants of $\mathbf{1}$ and $\mathbf{2}$ by introducing a moiety capable of forming a covalent bond with Cys797.

In order to correctly position a reactive functional group that would react with Cys797, we analyzed a set of unpublished, internally acquired crystal structures of members of this series bound to other kinases. Based on this analysis, we surmised that the aminopyrazine moiety forms the canonical set of hydrogen bonds to the hinge region of EGFR. This positioning would situate the benzimidazole ring below the P-loop and in the vicinity of the gatekeeper residue (see Supporting Information). We thus proposed that an appropriately situated electrophile on the benzimidazole $N$-substituent would be within striking distance of the nucleophilic cysteine, and would be capable of forming an irreversible covalent bond with the protein.

To test this hypothesis, the first compounds we prepared were direct analogs of $\mathbf{2}$, in which the $N$-ethyl group was replaced by acrylamide-substituted alkyl groups (3 and 4, Table 1). Neither of these compounds was a more effective inhibitor of EGFR $\mathrm{T} 790 \mathrm{M} / \mathrm{L} 858 \mathrm{R}$, however, as both were less potent in the enzyme assay than the initial reversible screening hit 2 . As a result of these data, we rationalized that the formation of a covalent bond between the protein and the acrylamide moieties of $\mathbf{3}$ and $\mathbf{4}$ was precluded by the conformational flexibility of the linking alkyl chain, and that rigidification of this chain might direct the acrylamide toward Cys797 and reduce the entropic penalty
Table 1. Acrylamide-Containing Aminopyrazine EGFR Inhibitors Targeting Cys $797^{a}$

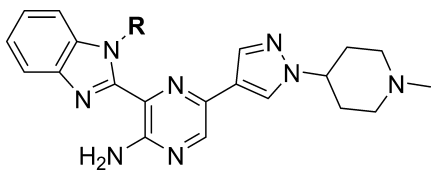

\begin{tabular}{|c|c|c|c|}
\hline Example & $\mathbf{R}$ & $\begin{array}{c}\text { DM enzyme } \\
\text { IC }_{50}(\mu \mathrm{M})\end{array}$ & $\begin{array}{c}\text { DM cellc } \\
\mathrm{EC}_{50}(\mu \mathrm{M})\end{array}$ \\
\hline 3 & & $2.20 \pm 1.10$ & $14.9 \pm 4.31$ \\
\hline 4 & & $0.20 \pm 0.03$ & $1.71 \pm 0.57$ \\
\hline 5 & & $<0.001$ & $0.014 \pm 0.01$ \\
\hline
\end{tabular}

${ }^{a}$ Data represents the average of at least two separate measurements \pm standard deviation. ${ }^{b} \mathrm{DM}=$ double mutant EGFR (T790M/L858R). ${ }^{c}$ NCI-H1975 cells with double mutant EGFR (T790M/L858R).

associated with achieving the desired transition state. In particular, we proposed that by incorporating the linking atoms into an aromatic ring, the rotational freedom of the alkyl linkers would be removed without adversely affecting binding to the ATP site of the kinase. Moreoever, since we have previously demonstrated that the reactivity of acrylamides is greatly affected by the electron-withdrawing ability of the nitrogen substituent, ${ }^{20}$ it was anticipated that this change would result in an inherently more reactive compound. Analysis of the published crystal structure of WZ4002, a previously described covalent EGFR inhibitor, ${ }^{12}$ bound to EGFR T790M suggested that metasubstitution of such a ring would effectively orient the acrylamide toward the cysteine residue (Supporting Information), maximizing the probability of covalent bond formation.

To test this hypothesis, we next prepared compound $\mathbf{5}$ (Scheme 1), in which the acrylamide and the benzimidazole ring are linked through a meta-substituted arene. The synthesis of this compound commenced with the preparation of aniline 6 , which was coupled to aminopyrazine carboxylate 7 followed by cyclization in refluxing acetic acid to give benzimidazole 8 . Suzuki coupling with a $N$-protected pyrazolopiperidine boronate ester followed by Boc-deprotection and reductive amination afforded the $\mathrm{N}$-methylpiperazine intermediate 9. Hydrolysis of the amide group followed by acylation with acryloyl chloride yielded the target compound 5. Gratifyingly, this compound was found to be a very potent inhibitor of EGFR T790M/L858R enzyme and also effectively inhibited the autophosphorylation of this double mutant EGFR in NCI-H1975 cells (Table 1). To further support our design hypothesis, we obtained a crystal structure of this compound bound in the ATP site of JAK3 (Figure 2), which has a methionine gatekeeper as well as a cysteine at the same position as in EGFR, ${ }^{5}$ and was thus used as a surrogate for EGFR T790M. As we had proposed, the aminopyrazine binds to the hinge region of the kinase, the pyrazolopiperidine resides in the solvent channel, and the acrylamide functionality has formed a covalent bond with the nucleophilic cysteine residue.

In light of the potency of $\mathbf{5}$ in NCI-H1975 cells, we next surveyed the effects of this compound in other cell lines containing EGFR of different mutation status (Table 2). In PC9 cells, which have an activating mutation (exon 19 deletion) in EGFR that would predict sensitivity to established EGFR 
Scheme 1. Synthesis of Compound $5^{a}$

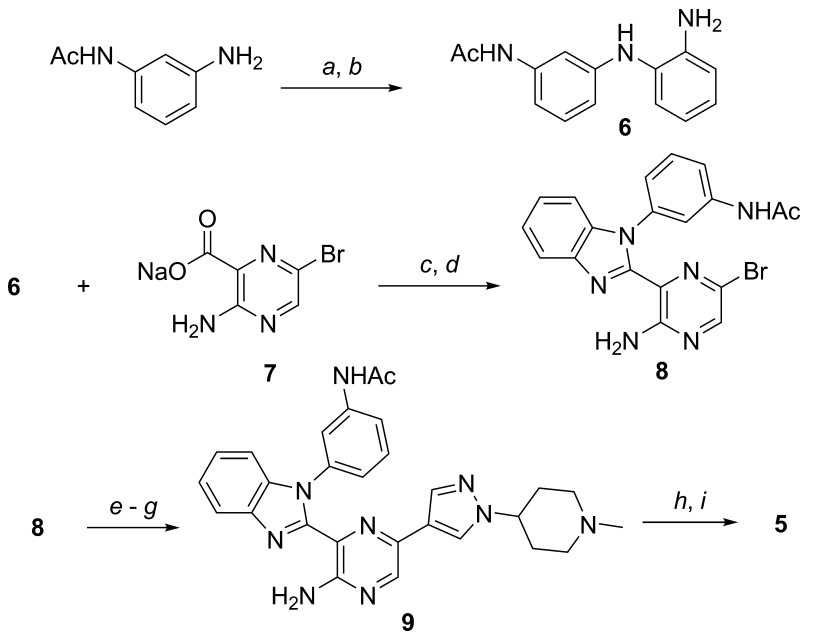

${ }^{a}$ Reagents and conditions: (a) 1-fluoro-2-nitrobenzene, 4-methylmorpholine, DMF, $125{ }^{\circ} \mathrm{C}$; (b) $\mathrm{Zn}, \mathrm{NH}_{4} \mathrm{Cl}, \mathrm{MeOH} / \mathrm{H}_{2} \mathrm{O}, 60{ }^{\circ} \mathrm{C}$; (c) HATU, DMF, rt; (d) glacial HOAc, $120{ }^{\circ} \mathrm{C}$; (e) tert-butyl 4-(4(4,4,5,5-tetramethyl-1,3,2-dioxaborolan-2-yl)-1H-pyrazol-1-yl)piperidine-1-carboxylate, $\mathrm{Pd}_{2}(\mathrm{dba})_{3}(5 \mathrm{~mol} \%)$, SPhos (5 mol \%), $\mathrm{Cs}_{2} \mathrm{CO}_{3}$, dioxane $/ \mathrm{H}_{2} \mathrm{O}, 100{ }^{\circ} \mathrm{C}$; (f) TFA, $\mathrm{CH}_{2} \mathrm{Cl}_{2}$, rt, then $\mathrm{NaHCO}_{3}$; (g) formaldehyde (37\% aqueous), $\mathrm{NaBH}_{3} \mathrm{CN}, \mathrm{MeOH}$, rt; (h) $2 \mathrm{~N}$ $\mathrm{HCl}, 100^{\circ} \mathrm{C}$; (i) acryloyl chloride, 4-methylmorpholine, EtOAc/DMF, rt.

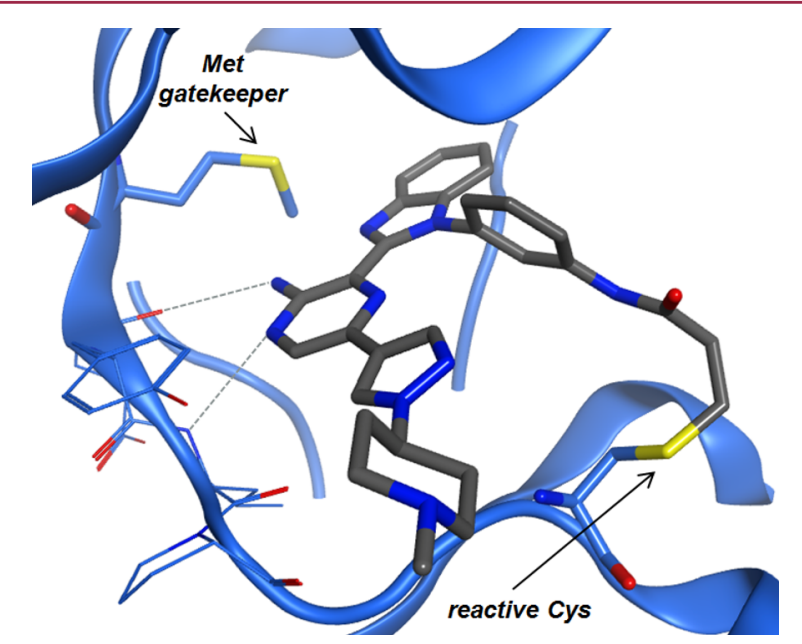

Figure 2. X-ray crystal structure of compound 5 bound to the ATP binding site of JAK3 (PDB ID 4V0G).

inhibitors such as gefitinib and erlotinib, this compound is similarly a very effective inhibitor of EGFR autophosphorylation. Moreover, these levels of cellular potency translate to pronounced antiproliferative effects in both cell lines in a 72-h assay $\left(\mathrm{GI}_{50}\right.$ for 5 in NCI-H1975 $=25 \mathrm{nM}$; PC9 GI $\left.50=16 \mathrm{nM}\right)$. Interestingly, in cell lines with EGFR WT, $\mathbf{5}$ is a much poorer inhibitor of EGFR autophosphorylation $\left(\mathrm{EC}_{50}\right.$ in LoVo $=0.98$ $\mu \mathrm{M})$ and cell proliferation $\left(\mathrm{GI}_{50}\right.$ in Calu6 $\left.=1.7 \mu \mathrm{M}\right)$. These margins of over 60 -fold relative to potency in NCI-H1975 cells are in line with our desire to identify an agent that would have an improved toxicity profile in the clinic.

To assess the overall kinome selectivity of $\mathbf{5}$, we subjected it to testing against a panel of 125 diverse kinases (see Supporting Information). At a concentration of $1 \mu \mathrm{M}, \mathbf{5}$ is moderately selective, demonstrating $>75 \%$ inhibition for only 19 of these
Table 2. Effects of Varying Benzimidazole Substitution on Activity of Activating Mutant, Double Mutant, and Wild-Type EGFR in Cells ${ }^{a}$

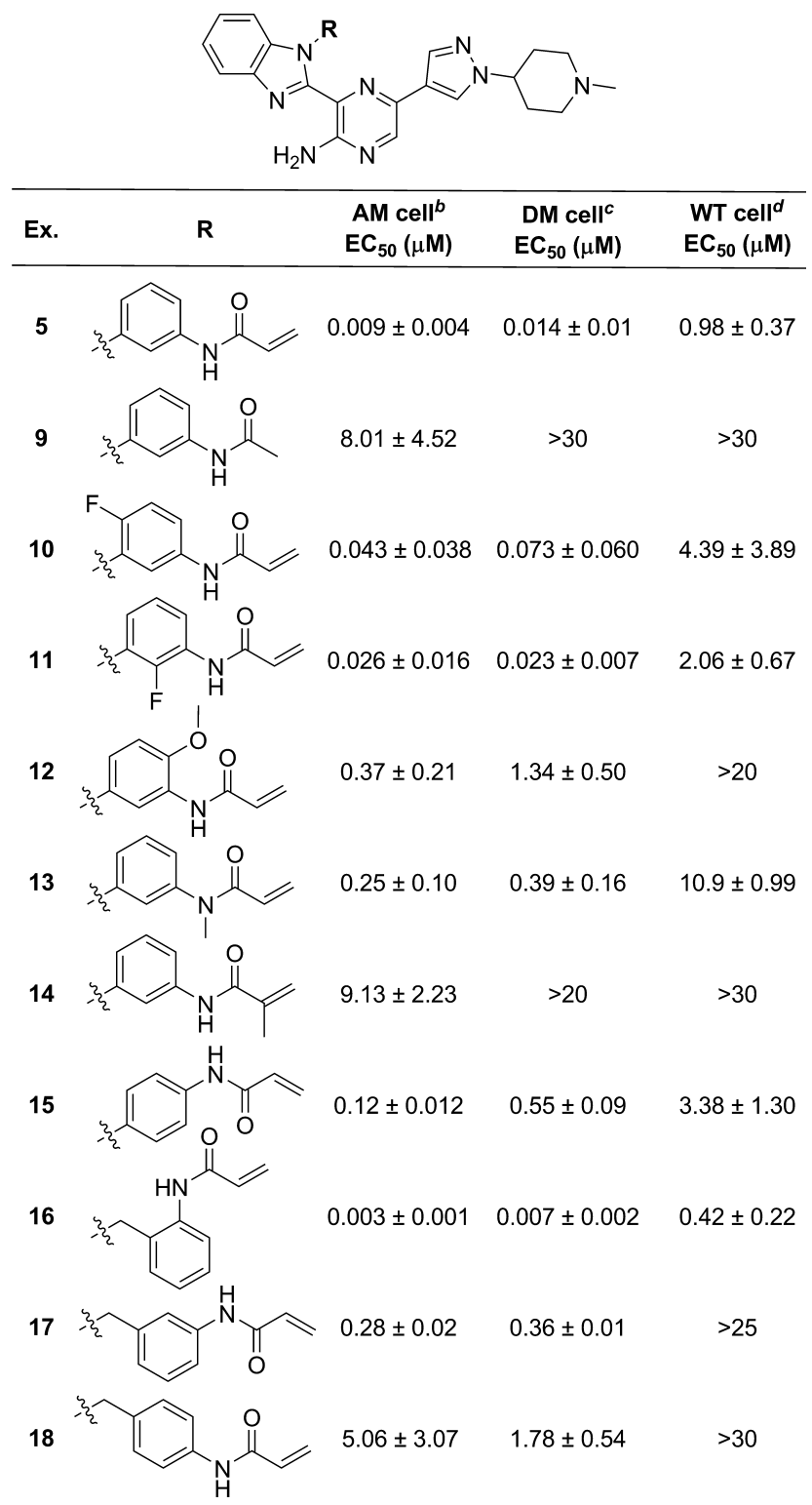

${ }^{a}$ Data represents the average of at least two separate measurements \pm standard deviation. ${ }^{b}$ PC9 cells with activating mutation (exon 19 deletion) in EGFR. ${ }^{c} \mathrm{NCI}-\mathrm{H} 1975$ cells with double mutant EGFR (T790M/L858R). ${ }^{d}$ LoVo cells with wild-type EGFR.

kinases (including EGFR WT, EGFR T790M/L858R, and JAK3) and $>50 \%$ inhibition for 31 kinases.

Despite the encouraging cellular profile of compound 5, we were concerned about the prospects of this compound for further progression as an orally available agent due to poor physical properties (solubility in $\mathrm{pH} 7.4$ buffer $<10 \mu \mathrm{M}$ ) and metabolic instability (human liver microsomes $\mathrm{CL}_{\text {int }}=120 \mu \mathrm{L} / \mathrm{min} / \mathrm{mg}$ ). As a result, we next set about exploring various modifications to the scaffold in order to develop a deeper understanding of structure-activity relationships and to assess the effects of these changes on key properties.

Compounds without the acrylamide moiety, such as acetamide 9, are largely devoid of cellular potency in these assays, thus reinforcing the need to bind irreversibly to the protein with this 
Table 3. Effects of Modifications to the Solvent Tail on Cellular Potency, Microsomal Stability, and Aqueous Solubility ${ }^{a}$

\begin{tabular}{|c|c|c|c|c|c|c|c|c|}
\hline Example & $\mathbf{R}$ & A & B & $\begin{array}{c}\text { AM cell }{ }^{b} \\
\mathrm{EC}_{50}(\mu \mathrm{M})\end{array}$ & $\begin{array}{c}\text { DM cell } \\
\mathrm{EC}_{50}(\mu \mathrm{M})\end{array}$ & $\begin{array}{c}\text { WT cell } \\
\mathrm{EC}_{50}(\mu \mathrm{M})\end{array}$ & $\begin{array}{c}\text { HLM CL } \mathrm{CL}_{\text {int }} \\
(\mu \mathrm{L} / \mathrm{min} / \mathrm{mg})^{e}\end{array}$ & $\begin{array}{c}\text { Solubility } \\
(\mu \mathrm{M}, \mathrm{pH} 7.4)^{f}\end{array}$ \\
\hline 19 & & $\mathrm{CH}$ & $\mathrm{N}$ & $0.010 \pm 0.006$ & $0.018 \pm 0.010$ & $4.39 \pm 1.33$ & 169 & 300 \\
\hline 20 & & $N$ & $\mathrm{CH}$ & $0.10 \pm 0.02$ & $0.15 \pm 0.06$ & $>15$ & 68 & 540 \\
\hline 21 & $-\xi-\mathrm{CH}_{3}$ & $\mathrm{CH}$ & $\mathrm{CH}$ & $0.009 \pm 0.003$ & $0.010 \pm 0.003$ & $1.07 \pm 0.41$ & 24 & $<10$ \\
\hline 22 & & $\mathrm{CH}$ & $\mathrm{CH}$ & $0.008 \pm 0.001$ & $0.012 \pm 0.001$ & $2.25 \pm 0.54$ & 54 & $<10$ \\
\hline 23 & & $\mathrm{CH}$ & $\mathrm{CH}$ & $0.022 \pm 0.005$ & $0.024 \pm 0.006$ & $5.00 \pm 1.40$ & 298 & $<10$ \\
\hline 24 & & $\mathrm{CH}$ & $\mathrm{CH}$ & $0.015 \pm 0.006$ & $0.015 \pm 0.001$ & $2.31 \pm 0.54$ & 60 & 30 \\
\hline 25 & & $\mathrm{CH}$ & $\mathrm{CH}$ & $0.016 \pm 0.004$ & $0.009 \pm 0.002$ & $1.96 \pm 0.39$ & 197 & $<10$ \\
\hline 26 & & $\mathrm{CH}$ & $\mathrm{CH}$ & $0.009 \pm 0.002$ & $0.014 \pm 0.005$ & $0.76 \pm 0.16$ & 37 & $<10$ \\
\hline 27 & & $\mathrm{CH}$ & $\mathrm{CH}$ & $0.023 \pm 0.0003$ & $0.022 \pm 0.001$ & $3.51 \pm 0.25$ & $>300$ & $<10$ \\
\hline 28 & & $\mathrm{CH}$ & $\mathrm{CH}$ & $0.018 \pm 0.005$ & $0.024 \pm 0.003$ & $3.00 \pm 0.66$ & $>300$ & $<10$ \\
\hline 29 & & $\mathrm{CH}$ & $\mathrm{CH}$ & $0.013 \pm 0.0001$ & $0.015 \pm 0.011$ & $1.14 \pm 0.18$ & 66 & 18 \\
\hline
\end{tabular}

${ }^{a}$ Data represents the average of at least two separate measurements \pm standard deviation. ${ }^{b}$ PC9 cells with activating mutation (exon 19 deletion) in EGFR. ${ }^{c}$ NCI-H1975 cells with double mutant EGFR (T790M/L858R). ${ }^{d}$ LoVo cells with wild-type EGFR. ${ }^{e}$ Intrinsic clearance in the presence of human liver microsomes. ${ }^{f}$ Solubility in $\mathrm{pH} 7.4$ buffer of material obtained from dried DMSO stock solution.

scaffold. Small, lipophilic substituents on the acrylamide-bearing aromatic ring appear to be tolerated to a varying extent with respect to cellular potency $(\mathbf{1 0 - 1 2}$, Table 2), although as expected these modifications had little beneficial impact on solubility (all $<10 \mu \mathrm{M})$. It is noteworthy that methoxysubstitution at the position para-to the benzimidazole (as in compound 12) results in a less potent inhibitor across all cell lines examined, possibly by destabilizing the coplanar orientation between the acrylamide and arene observed with covalently bound 5 (Figure 2), or through decreased acrylamide electrophilicity due to the electron-donating nature of this group. Similarly, methylation of either the nitrogen or the $\alpha$-carbon of the acrylamide has been shown to decrease the reactivity of these groups toward sulfur nucleophiles, ${ }^{20}$ and thus these modifications lead to considerable loss of potency (13-14). Moving the acrylamide from the meta- to the para-position on the ring (15) likewise results in a loss in potency, reinforcing the importance of accurately locating the reactive electrophile on the scaffold to achieve the profile observed with $\mathbf{5}$.

In our initial screen to identify selective inhibitors of EGFR T790M, we noted that analogs of $\mathbf{1}$ and $\mathbf{2}$ in which the benzimidazole ring nitrogen was decorated with substituted benzylic groups also bound effectively in a reversible fashion to the kinase (data not shown). Following the design rationale for compound 5, we therefore also prepared compounds 16-18 in which an acrylamide moiety was appended onto a benzimidazole $\mathrm{N}$-benzyl group. We found that the ortho-substituted compound 16 demonstrated comparable cellular potency to 5 in the wildtype-, activating mutant-, and double mutant-EGFR cell lines. Moreover, due to a significant reduction in lipophilicity compared to 5 (cLogP 2.0 vs 3.5), 16 has an improved ligand lipophilicity efficiency (LLE) in the NCI-H1975 cell line (6.1 vs 4.3) along with slightly higher aqueous solubility $(35 \mu \mathrm{M})$. The meta- and para-substituted analogs (17-18) were markedly less effective inhibitors, presumably due to improper alignment of the acrylamide moiety with the reactive cysteine residue of the protein. In spite of the promising profile of 16 , we found that this compound had chemical stability issues not seen with compound $\mathbf{5}$ and its congeners, and thus was not progressed any further.

Having established the relatively tight SAR around the acrylamide moiety and the aromatic ring to which it is attached, we next turned our attention to the benzimidazole portion of the scaffold. We envisioned that the introduction of nitrogen atoms into the carbocyclic ring would result in decreased lipophilicity and improved physical properties, and indeed the azabenzimidazole compounds 19 and 20 both had significantly enhanced aqueous solubility relative to $\mathbf{5}$ (Table 3 ). Interestingly, compound 19 had cellular potency in the activating mutant- 
and double mutant-EGFR cell assays comparable to $\mathbf{5}$ (and thus a significant boost in LLE to 5.3), as well as an improved margin between activity in the double mutant and wild-type cell lines. Unfortunately, however, these improvements were offset by a notable decrease in overall kinase selectivity that we felt would preclude further progression of this compound (see Supporting Information).

With respect to the poor microsomal stability of $\mathbf{5}$, we suspected that the high intrinsic clearance was in large part due to $\mathrm{N}$-demethylation of the piperidine ring. Attempts to eliminate this metabolic liability by preparation of unsubstituted $\mathrm{N}-\mathrm{H}$ compounds were unsuccessful, presumably due to the incompatibility of a nucleophilic, unsubstituted piperidine with an electrophilic acrylamide moiety. To address the issue of metabolic instability, therefore, we explored other modifications to the substituted pyrazole solvent tail (21-29, Table 3). A variety of structural changes are tolerated at this position, with little impact on the cellular potency profile relative to compound 5. Some of these modifications, such as those in which the piperidine ring is removed altogether $(\mathbf{2 1}, \mathbf{2 2})$, did result in improved (albeit still modest) stability in the presence of human liver microsomes. Other modifications, such as an increase in the steric bulk of the piperidine $N$-substituent or acylation of the basic center, had mixed results with respect to microsomal stability. None of these changes made to the solvent tail portion of the molecule resulted in significant increases in aqueous solubility, however, and thus did not constitute substantial improvements with respect to compound $\mathbf{5}$.

Despite the physical property limitations of 5, a $50 \mathrm{mg} / \mathrm{kg}$ dose of this compound administered orally to nude mice resulted in free plasma concentrations sufficient to cover the cellular $\mathrm{EC}_{50}$ for both activating mutant and double mutant EGFR cell lines for a period of roughly $6 \mathrm{~h}$ (Supporting Information). Given the irreversible nature of this compound, we hypothesized that this would be a sufficient duration of exposure to inactivate the kinase and demonstrate antitumor effects in vivo. Moreover, the inhibition of other kinases to which 5 binds reversibly would be transient, and thus antitumor activity in models derived from these cell lines would most likely be attributable to EGFR inhibition. Therefore, we conducted efficacy experiments with this compound in immunocompromised mice bearing A431 (wild-type EGFR), PC9 (activating mutant EGFR), and NCIH1975 (double mutant EGFR) tumor xenografts. Compound 5 is highly efficacious in models of EGFR mutant lung cancer, inducing tumor regressions in both the PC9 and NCI-H1975 xenograft studies (Table 4). Consistent with the lack of wild-type EGFR cellular potency we observe in vitro, $\mathbf{5}$ does not show any statistically significant antitumor activity in vivo in the A431 model. In contrast, gefitinib is efficacious in A431 and PC9 xenografts at a clinically relevant dose, but does not show any antitumor activity in the EGFR T790M-harboring H1975 model at a daily dose well above what would be tolerated in human patients. $^{20}$

In conclusion, we have discovered a novel series of compounds that covalently bind to and inhibit the kinase activity of mutant forms of EGFR (both activating mutant and double mutant) in cells. This inhibition results in antiproliferative effects in cancer cell lines harboring mutant forms of EGFR, and translates into pronounced antitumor activity in corresponding in vivo xenograft models. Importantly, these compounds are much less effective inhibitors of wild-type EGFR (in vitro and in vivo), suggesting that efficacious doses could be realized without encountering the toxicity associated with established EGFR inhibitors.
Table 4. In Vivo Antitumor Efficacy Data from Xenograft Studies for Compound 5 and gefitinib ${ }^{a}$

$\begin{array}{clcl}\begin{array}{c}\text { Compound/ } \\ \text { Dose }\end{array} & \begin{array}{c}\text { A431 (WT } \\ \text { EGFR) \% TGI }\end{array} & \begin{array}{c}\text { PC9 (AM } \\ \text { EGFR) \% TGI }\end{array} & \begin{array}{c}\text { NCI-H1975 (DM } \\ \text { EGFR) \%TGI }\end{array} \\ \mathbf{5}(50 & 21(\mathrm{NS}) & 238(p<0.001) & 117(p<0.001) \\ \mathrm{mg} / \mathrm{kg} / \text { day }) & & & \\ \text { gefitinib }(6.25 & 79(p<0.001) & 142(p<0.001) & 8(\mathrm{NS})^{b}\end{array}$

${ }^{a}$ Antitumor efficacy in A431 (wild-type-EGFR), PC9 (activating mutant EGFR), and NCI-H1975 (double mutant EGFR) xenografts as measured by tumor growth inhibition (TGI) in compound-treated animals relative to an untreated (vehicle only) control group after 7 days of once-daily oral dosing. TGI $>100 \%$ indicates tumor regression from the initial volume. Statistical significance ( $p$ value) was calculated from compound-treated and vehicle groups using a one-tailed $t$-test. NS indicates that the antitumor activity was not statistically significant compared to the vehicle-treated group. ${ }^{b}$ Data from a $100 \mathrm{mg} / \mathrm{kg} /$ day oral dose of gefitinib.

\section{ASSOCIATED CONTENT}

\section{S Supporting Information}

The Supporting Information is available free of charge on the ACS Publications website at DOI: 10.1021/acsmedchemlett.6b00058.

Analysis of EGFR T790M/L858R vs WT selectivity for aminopyrazine scaffold, graphical depiction of the structure-based design of compound 5, synthetic protocols for the preparation of compound 5, analytical and spectroscopic characterization data for compounds 3-29, assessment of chemical reactivity for representative compounds from this paper, protocols for enzyme and cell assays, summary of kinase selectivity data for compounds 5 and 19, mouse pharmacokinetics for compound 5, and crystallographic collection and refinement data. (PDF)

\section{AUTHOR INFORMATION}

\section{Corresponding Author}

*(E.J.H.) Phone: (781) 839-4153. E-mail: edward.hennessy@ astrazeneca.com.

\section{Notes}

The authors declare no competing financial interest.

\section{ACKNOWLEDGMENTS}

We are grateful to Ray Finlay, Richard Ward, Sam Butterworth, and Rob Bradbury for helpful discussions. We also thank Proteros for obtaining the X-ray crystal structure described in this paper, and Sharon Tentarelli for analytical support.

\section{REFERENCES}

(1) Pao, W.; Chmielecki, J. Rational, biologically based treatment of EGFR-mutant non-small-cell lung cancer. Nat. Rev. Cancer 2010, 10, 760-774.

(2) Engelman, J. A.; Jänne, P. A. Mechanisms of Acquired Resistance to Epidermal Growth Factor Receptor Tyrosine Kinase Inhibitors in NonSmall Cell Lung Cancer. Clin. Cancer Res. 2008, 14, 2895-2899.

(3) Oxnard, G. R.; Arcila, M. E.; Chmielecki, J.; Ladanyi, M.; Miller, V. A.; Pao, W. New Strategies in Overcoming Acquired Resistance to Epidermal Growth Factor Receptor Tyrosine Kinase Inhibitors in Lung Cancer. Clin. Cancer Res. 2011, 17, 5530-5537.

(4) Kobayashi, S.; Boggon, T. J.; Dayaram, T.; Jänne, P. A.; Kocher, O.; Meyerson, M.; Johnson, B. E.; Eck, M. J.; Tenen, D. G.; Halmos, B. 
EGFR Mutation and Resistance of Non-Small-Cell Lung Cancer to Gefitinib. N. Engl. J. Med. 2005, 352, 786-792.

(5) Yun, C.-H.; Mengwasser, K. E.; Toms, A. V.; Woo, M. S.; Greulich, H.; Wong, K.-K.; Meyerson, M.; Eck, M. J. The T790M mutation in EGFR kinase causes drug resistance by increasing the affinity for ATP. Proc. Natl. Acad. Sci. U. S. A. 2008, 105, 2070-2075.

(6) Herbst, R. S.; LoRusso, P. M.; Purdom, M.; Ward, D. Dermatologic Side Effects Associated with Gefitinib Therapy: Clinical Experience and Management. Clin. Lung Cancer 2003, 4, 366-369.

(7) Ou, S.-H. I. Second-generation irreversible epidermal growth factor receptor (EGFR) tyrosine kinase inhibitors (TKIs): A better mousetrap? A review of the clinical evidence. Crit. Rev. Oncol. Hematol. 2012, 83, 407-421.

(8) Galvani, E.; Alfieri, R.; Giovannetti, E.; Cavazzoni, A.; La Monica, S.; Galetti, M.; Fumarola, C.; Bonelli, M.; Mor, M.; Tiseo, M.; Peters, G. J.; Petronini, P. G.; Ardizzoni, A. Epidermal Growth Factor Receptor Tyrosine Kinase Inhibitors: Current Status and Future Perspectives in the Development of Novel Irreversible Inhibitors for the Treatment of Mutant Non-small Cell Lung Cancer. Curr. Pharm. Des. 2013, 19, 818832.

(9) Li, S.-N.; Li, H.-Q. Epidermal growth factor receptor inhibitors: a patent review (2010 - present). Expert Opin. Ther. Pat. 2014, 24, 309321.

(10) Sequist, L. V.; Besse, B.; Lynch, T. J.; Miller, V. A.; Wong, K. K.; Gitlitz, B.; Eaton, K.; Zacharchuk, C.; Freyman, A.; Powell, C.; Ananthakrishnan, R.; Quinn, S.; Soria, J.-C. Neratinib, an Irreversible Pan-ErbB Receptor Tyrosine Kinase Inhibitor: Results of a Phase II Trial in Patients With Advanced Non-Small-Cell Lung Cancer. J. Clin. Oncol. 2010, 28, 3076-3083.

(11) Miller, V. A.; Hirsh, V.; Cadranel, J.; Chen, Y.-M.; Park, K.; Kim, S.-W.; Zhou, C.; Su, W.-C.; Wang, M.; Sun, Y.; Heo, D. S.; Crino, L.; Tan, E.-H.; Chao, T.-Y.; Shahidi, M.; Cong, X. J.; Lorence, R. M.; Yang, J. C.-H. Afatinib versus placebo for patients with advanced, metastatic non-small-cell lung cancer after failure of erlotinib, gefitinib, or both, and one or two lines of chemotherapy (LUX-Lung 1): a phase $2 b / 3$ randomised trial. Lancet Oncol. 2012, 13, 528-538.

(12) Zhou, W.; Ercan, D.; Chen, L.; Yun, C.-H.; Li, D.; Capelletti, M.; Cortot, A. B.; Chirieac, L.; Iacob, R. E.; Padera, R.; Engen, J. R.; Wong, K.-K.; Eck, M. J.; Gray, N. S.; Jänne, P. A. Novel mutant-selective EGFR kinase inhibitors against EGFR T790M. Nature 2009, 462, 1070-1074.

(13) Zhou, W.; Ercan, D.; Jänne, P. A.; Gray, N. S. Discovery of selective irreversible inhibitors for EGFR-T790M. Bioorg. Med. Chem. Lett. 2011, 21, 638-643.

(14) Zhou, W.; Liu, X.; Tu, Z.; Zhang, L.; Ku, X.; Bai, F.; Zhao, Z.; Xu, Y.; Ding, K.; Li, H. Discovery of Pteridin-7 $(8 H)$-one-Based Irreversible Inhibitors Targeting the Epidermal Growth Factor Receptor (EGFR) Kinase T790M/L858R Mutant. J. Med. Chem. 2013, 56, 7821-7837.

(15) Walter, A. O.; Sjin, R. T. T.; Haringsma, H. J.; Ohashi, K.; Sun, J.; Lee, K.; Dubrovskiy, A.; Labenski, M.; Zhu, Z.; Wang, Z.; Sheets, M.; St Martin, T.; Karp, R.; van Kalken, D.; Chaturvedi, P.; Niu, D.; Nacht, M.; Petter, R. C.; Westlin, W.; Lin, K.; Jaw-Tsai, S.; Raponi, M.; Van Dyke, T.; Etter, J.; Weaver, Z.; Pao, W.; Singh, J.; Simmons, A. D.; Harding, T. C.; Allen, A. Discovery of a Mutant-Selective Covalent Inhibitor of EGFR that Overcomes T790M-Mediated Resistance in NSCLC. Cancer Discovery 2013, 3, 1404-1415.

(16) Tjin Tham Sjin, R.; Lee, K.; Walter, A. O.; Dubrovskiy, A.; Sheets, M.; St. Martin, T.; Labenski, M. T.; Zhu, Z.; Tester, R.; Karp, R.; Medikonda, A.; Chaturvedi, P.; Ren, Y.; Haringsma, H.; Etter, J.; Raponi, M.; Simmons, A. D.; Harding, T. C.; Niu, D.; Nacht, M.; Westlin, W. F.; Petter, R. C.; Allen, A.; Singh, J. In Vitro and In Vivo Characterization of Irreversible Mutant-Selective EGFR Inhibitors That Are Wild-Type Sparing. Mol. Cancer Ther. 2014, 13, 1468-1479.

(17) Wurz, R. P.; Pettus, L. H.; Ashton, K.; Brown, J.; Chen, J. J.; Herberich, B.; Hong, F.-T.; Hu-Harrington, E.; Nguyen, T.; St. Jean, D. J., Jr.; Tadesse, S.; Bauer, D.; Kubryk, M.; Zhan, J.; Cooke, K.; Mitchell, P.; Andrews, K. L.; Hsieh, F.; Hickman, D.; Kalyanaraman, N.; Wu, T.; Reid, D. L.; Lobenhofer, E. K.; Andrews, D. A.; Everds, N.; Guzman, R.; Parsons, A. T.; Hedley, S. J.; Tedrow, J.; Thiel, O. R.; Potter, M.; Radinsky, R.; Beltran, P. J.; Tasker, A. S. Oxopyrido[2,3-d]pyrimidines as Covalent L858R/T790M Mutant Selective Epidermal Growth Factor Receptor (EGFR) Inhibitors. ACS Med. Chem. Lett. 2015, 6, 987-992. (18) Engel, J.; Richters, A.; Getlik, M.; Tomassi, S.; Keul, M.; Termathe, M.; Lategahn, J.; Becker, C.; Mayer-Wrangowski, S.; Grütter, C.; Uhlenbrock, N.; Krüll, J.; Schaumann, N.; Eppmann, S.; Kibies, P.; Hoffgaard, F.; Heil, J.; Menninger, S.; Ortiz-Cuaran, S.; Heuckmann, J. M.; Tinnefeld, V.; Zahedi, R. P.; Sos, M. L.; Schultz-Fademrecht, C.; Thomas, R. K.; Kast, S. M.; Rauh, D. Targeting Drug Resistance in EGFR with Covalent Inhibitors: A Structure-Based Design Approach. J. Med. Chem. 2015, 58, 6844-6863.

(19) Cheng, H.; Nair, S. K.; Murray, B. W.; Almaden, C.; Bailey, S.; Baxi, S.; Behenna, D.; Cho-Schultz, S.; Dalvie, D.; Dinh, D. M.; Edwards, M. P.; Feng, J. L.; Ferre, R. A.; Gajiwala, K. S.; Hemkens, M. D.; JacksonFisher, A.; Jalaie, M.; Johnson, T. O.; Kania, R. S.; Kephart, S.; Lafontaine, J.; Lunney, B.; Liu, K. K.-C.; Liu, Z.; Matthews, J.; Nagata, A.; Niessen, S.; Ornelas, M. A.; Orr, S. T. M.; Pairish, M.; Planken, S.; Ren, S.; Richter, D. T.; Ryan, K.; Sach, N.; Shen, H.; Smeal, T.; Solowiej, J.; Sutton, S.; Tran, K.; Tseng, E.; Vernier, W.; Walls, M.; Wang, S.; Weinrich, S. L.; Xin, S.; Xu, H.; Yin, M.-J.; Zientek, M.; Zhou, R.; Kath, J. C. Discovery of 1- $\{(3 R, 4 R)-3-[(\{5-C h l o r o-2-[(1-m e t h y l-1 H$-pyrazol-4yl)amino]-7H-pyrrolo[2,3-d] pyrimidin-4-yl $\}$ oxy)methyl]-4-methoxypyrrolidin-1-yl\}prop-2-en-1-one (PF-06459988), a Potent, WT Sparing, Irreversible Inhibitor of T790M-Containing EGFR Mutants. J. Med. Chem. 2016, 59, 2005-2024.

(20) Ward, R. A.; Anderton, M. J.; Ashton, S.; Bethel, P. A.; Box, M.; Butterworth, S.; Colclough, N.; Chorley, C. G.; Chuaqui, C.; Cross, D. A. E.; Dakin, L. A.; Debreczeni, J. É.; Eberlein, C.; Finlay, M. R. V.; Hill, G. B.; Grist, M.; Klinowska, T. C. M.; Lane, C.; Martin, S.; Orme, J. P.; Smith, P.; Wang, F.; Waring, M. J. Structure- and Reactivity-Based Development of Covalent Inhibitors of the Activating and Gatekeeper Mutant Forms of the Epidermal Growth Factor Receptor (EGFR). J. Med. Chem. 2013, 56, 7025-7048.

(21) Cross, D. A. E.; Ashton, S. E.; Ghiorghiu, S.; Eberlein, C.; Nebhan, C. A.; Spitzler, P. J.; Orme, J. P.; Finlay, M. R. V.; Ward, R. A.; Mellor, M. J.; Huges, G.; Rahi, A.; Jacobs, V. N.; Brewer, M. R.; Ichihara, E.; Sun, J.; Jin, H.; Ballard, P.; Al-Kadhimi, K.; Rowlinson, R.; Klinowska, T.; Richmond, G. H. P.; Cantarini, M.; Kim, D.-W.; Ranson, M. R.; Pao, W. AZD9291, an Irreversible EGFR TKI, Overcomes T790M-Mediated Resistance to EGFR Inhibitors in Lung Cancer. Cancer Discovery 2014, 4, 1046-1061.

(22) Finlay, M. R. V.; Anderton, M.; Ashton, S.; Ballard, P.; Bethel, P. A.; Box, M. R.; Bradbury, R. H.; Brown, S. J.; Butterworth, S.; Campbell, A.; Chorley, C.; Colcough, N.; Cross, D. A. E.; Currie, G. S.; Grist, M.; Hassall, L.; Hill, G. B.; James, D.; James, M.; Kemmitt, P.; Klinowska, T.; Lamont, G.; Lamont, S. G.; Martin, N.; McFarland, H. L.; Mellor, M. J.; Orme, J. P.; Perkins, D.; Perkins, P.; Richmond, G.; Smith, P.; Ward, R. A.; Waring, M. J.; Whittaker, D.; Wells, S.; Wrigley, G. L. Discovery of a Potent and Selective EGFR Inhibitor (AZD9291) of Both Sensitizing and T790M Resistance Mutations That Spares the Wild Type Form of the Receptor. J. Med. Chem. 2014, 57, 8249-8267.

(23) Barlaam, B. C.; Chuaqui, C. E.; Delouvrie, B.; Ouvry, G.; Wang, T.; Winter, J. J. G. 2-Pyrazinylbenzimidazole Derivatives as Receptor Tyrosine Kinase Inhibitors. WIPO Patent WO2009024825, 2009.

(24) Singh, J.; Evans, E.; Hagel, M.; Labinski, M.; Dubrovskiy, A.; Nacht, M.; Petter, R. C.; Prasad, A.; Sheets, M., St; Martin, T.; Sjin, R. T. T.; Westlin, W.; Zhu, Z. Superiority of a novel EGFR targeted covalent inhibitor over its reversible counterpart in overcoming drug resistance. MedChem Comm 2012, 3, 780-783.

\section{NOTE ADDED AFTER ASAP PUBLICATION}

This article was published post-ASAP on March 24, 2016 with an error in Scheme 1. The corrected version was reposted on April 7, 2016. 